\title{
IMPLEMENTATION OF THE PROJECT BASED LEARNING METHODOLOGY IN THE "MATERIALS. DESIGN AND RESTYLING" SUBJECT
}

\author{
Daniel Garcia-Garcia1, Nestor Montanes ${ }^{1}$, Luis Quiles-Carrillo¹, Juan Ivorra- \\ Martinez ${ }^{1}$, Raquel Sanchis ${ }^{2}$ \\ ${ }^{1}$ Dpto. de Ingeniería Mecánica y de Materiales, Escuela Politécnica Superior de Alcoy. \\ Universitat Politècnica de València (SPAIN) \\ ${ }^{2}$ Dpto. de Organización de Empresas, Escuela Politécnica Superior de Alcoy. Universitat \\ Politècnica de València (SPAIN)
}

\begin{abstract}
The implementation of the European Higher Education Area (EHEA) resulted in a change in the concept of teaching-learning, from a traditional teacher-centered model to a current model focused on student learning. In this new model, the student takes an active role in acquiring competencies to process information, while the teacher is the facilitator of learning. In competence-based teaching, knowledge is approached through its interrelationship with other elements and at the same time bringing into play both knowledge and skills, abilities, and values, thus contributing to learning of great relevance to be transferred to the professional activity. Within the framework of the EHEA, the Project Based Learning (PBL) methodology is an effective tool for the acquisition of knowledge and skills that society is demanding from students, preparing them for their professional future.
\end{abstract}

The PBL is a learning methodology in continuous growth and evolution, becoming one of the most used methodologies in the current educational systems. This methodology is focused on the resolution of projects based on real problems by the students, mainly combined in groups. The PBL methodology allows students to acquire knowledge, develop different specific skills, increase their analysis and synthesis capabilities, and the development of research skills. In addition, PBL offers a number of advantages, as it allows students to become protagonists of their own learning, encouraging teamwork and leadership, and generating an active, dynamic, and participatory teaching environment in which feedback occurs between teachers and students, contributing to improved student learning. For all these reasons, it is considered that this learning methodology can be interesting and appropriate for its implementation in university degree subjects, as it allows students to prepare for real situations that they will later experience in their professional lives.

The main aim of the present work is to describe the experience of the application of the PBL learning method in the subject of "Materials. Design and Restyling", an optative subject framed within the module of "Design and Engineering of Vehicles" belonging to the Mechanical Engineering Degree taught at the Higher Polytechnic School of Alcoy of the Universitat Politècnica de València (UPV). In this case for the implementation of the PBL methodology, the redesign and analysis of a part of the automotive sector was proposed as a project to be carried out by the students.

Keywords: Project Based Learning, Competence-based teaching, Active learning, Teamwork.

\section{INTRODUCTION}

The teaching-learning process is defined as the "coherent set of techniques and actions, logically coordinated to direct the student's learning towards certain objectives" [1]. In the framework of the European Higher Education Area (EHEA) this concept is modified from a traditional model centered on the teacher, to a current model, centered on student learning. The student assumes an active role by acquiring information processing skills while the teacher is the facilitator of learning. Teaching by competencies requires starting from a learning process in which the person has to carry out specific tasks in a given context in order to acquire, through them, basic competencies for his or her personal development throughout life [2]. In competence-based teaching, knowledge is approached in a different way, through its interrelationship with other elements and by bringing into play both knowledge and skills, abilities and values, thus contributing to learning of great relevance to be transferred to the professional activity [3]. Competency-based learning enriches methodologies, with greater monitoring and tutoring of students, both individually and in groups. Regarding the teachers, it 
should be noted that their role in the teaching-learning process is significantly modified and they are focused on tasks of organization, monitoring and evaluation of student learning. Among the competence-based learning methodologies promoted by the European Higher Education Area, the Project Based Learning (PBL) methodology stands out, which is an effective tool for the acquisition of knowledge and skills that society is demanding from students, preparing them for their professional future [4].

Project Based Learning (PBL) is a teaching methodology focused on students as the protagonists of their own research-based learning, in which students, combined in groups, carry out resolution projects based on real situations. More specifically, PBL methodology is a type of instruction that allows students to conduct research, integrate theory and practice, and apply knowledge and skills to develop a viable solution to a defined problem $[5,6]$. The main result of this methodology is that students develop deeper levels of understanding and new skills that will help them in the educational context and in their future professional work [4]. In addition, this methodology has other advantages, among which are [7]:

- Increases student motivation and participation.

- Promotes teamwork and leadership.

- Improves the student's knowledge of the field.

- Increases their ability and use of problem-solving strategies.

- Generates greater development of professional skills.

- Generates a deeper learning about the field.

- Increases critical capacity for information analysis.

- Increases social and communication skills.

Regarding the teacher, his/her role in the PBL methodology is to act as a tutor and facilitator of the processes that are developed, to listen to the students, to make the appropriate criticism and objections, to promote group work, to formulate the appropriate questions to direct the solution, to guide in the use of the sources of information and to establish a good classroom climate [8].

Considering all these reasons described, the authors decided to implement the PBL teaching methodology in one of the optional subjects of the last year of the Mechanical Engineering Degree with the aim of preparing students for possible real situations that they will later experience in their professional life. Thus, the main aim of the present work is to describe the experience of the application of the PBL learning method in the subject of "Materials. Design and Restyling", an optative subject framed within the module of "Design and Engineering of Vehicles" belonging to the Mechanical Engineering Degree taught at the Higher Polytechnic School of Alcoy (EPSA) of the Universitat Politècnica de València (UPV). The application of the PBL methodology in such a subject is framed within the Institutional Educational Innovation and Improvement Project (PIME) that it is currently being developed at EPSA-UPV. The objective of this PIME Project is to develop competences-based learning, through the implementation of the PBL methodology [9]. EPSA-UPV imparts 6 bachelors' degrees: (i) Business Administration and Management; (ii) Electrical Engineering; (iii) Industrial Design and Product Development Engineering; (iv) Computer Engineering; (v) Mechanical Engineering; and (vi) Chemical Engineering and this contribution, as aforementioned, has been applied to the mechanical one. The bachelor's degrees consist of 4 years and the PBL methodology is being implemented in the $3^{\text {rd }}$ and $4^{\text {th }}$ courses. The duration of the PIME Project is two years, the first one (2019-2020) was characterized by (i) the identification of the subjects susceptible to be taught through PBL and (ii) the definition and design of the different PBL models in the bachelors' degrees while the second year (2020-2021) is focused on the implementation of the PBL models and the assessment of such an implementation. Readers are referred to PBL models defined in the different degrees of the PIME Project such as Computer Engineering [10-11]; Mechanical Engineering [12-13-14]; Chemical Engineering [15]; among others.

In this case for the implementation of the PBL methodology, the redesign and analysis of a part of the automotive sector was proposed as a project to be carried out by the students.

\section{CONTEXT}

The subject "Materials. Design and Restyling" is part of an optional mention given in the last course of the Mechanical Engineering Degree. These studies are carried out at the Higher Polytechnic School of 
Alcoy of the Universitat Politècnica de València (UPV). This mention is called "Design and Engineering of Vehicles" and is composed of 7 subjects that add up to a total of 36 credits, among which is "Materials. Design and Restyling". The students of the fourth course can choose between four different mentions, but they have to take and pass all the subjects of the chosen mention.

The subject "Materials. Design and Restyling" has 6 ECTS (European Credit Transfer and Accumulation System) credits distributed in 3 ECTS credits of Theory and 3 ECTS credits of Practice. It is offered in the first quarter of the fourth year and the average number of students matriculated per course in the last few years is 25 .

The main purpose of this subject is to introduce students the concept of "Restyling" in the automotive sector. Many changes introduced to vehicles and their designs in recent decades have been promoted by the development of new materials with improved properties, such as greater mechanical resistance and lower weight. For this reason, one of the central issues to be treated in this subject is the materials currently used in the automotive sector. But other objectives derived from restyling are also pursued, such as understanding how to make a correct material selection for the new part or product to be redesigned, using specific software to carry out simulations of the stresses to which this new part or product will be subjected, and mastering the techniques of Non-Destructive Testing in order to be able to analyse the in-service behaviour of the parts - products designed and manufactured, and thus be able to corroborate the validity of the design and selection of materials carried out.

\section{OBJECTIVES}

Within the framework of the PBL methodology, the general objective is that students, divided into work groups, carry out a project consisting of the redesign and manufacture of the prototype of a component, preferably from the automotive sector. This project is conceived as the backbone of the subject that is nourished by all the concepts seen both in the theory part, as well as the learning, skills and abilities acquired in the practice part.

The partial objectives pursued with the proposed project are:

- Modeling through CAD (Computer Aided Design) the chosen piece.

- Select the most suitable materials for the redesign of the piece.

- Redesign the piece.

- Simulate through CAE (Computer Aided Engineering) the new redesigned part with the selected materials.

- Manufacture a functional prototype.

\section{METHODOLOGY}

The Teaching Project of the subject "Materials. Design and Restyling" is structured in four Didactic Units, which are briefly described below:

- The first of the Didactic Units will include an introduction to the concept of "Restyling", a brief presentation of the evolution in designs and materials used in vehicles in general, and in the automotive sector in particular, and a very general presentation of the importance of making an adequate selection of materials.

- The second Didactic Unit will present the main materials used in the automotive sector, specifically the use of polymeric materials, composite materials, metals and special alloys and ceramic materials, including in some cases the description of the production processes, as well as certain economic, aesthetic, and environmental aspects of these materials.

- The third Didactic Unit will deal with Material Selection, Stress Simulations and Non-Destructive Testing (NDT). Although the selection of the most appropriate material is one of the first steps in the process of designing or redesigning of a piece or product, NDTs can provide information on the evolution and status of this new piece or product once it is being used, that is, when it is in service, information that can confirm whether or not the design or redesign, as well as the material selected, has been appropriate, but without the associated cost of destructive testing. On the other hand, stress simulations through specific software can help both in the design 
process and in the selection of the most appropriate material in the initial phases, saving the costs associated with the manufacture and characterization of real pieces.

- Finally, the last Didactic Unit will deal with aspects related to Design and Restyling in the automotive sector.

As part of the continuous evaluation of the subject and within the framework of the application of the PBL methodology, as mentioned above, students are proposed to carry out a project by groups focused on the design or redesign of a piece, preferably from the automotive sector, and students must, among other things, manufacture a prototype of this piece. It is important to mention that the correct elaboration of this project requires the use and application of the diverse knowledge that the students will be acquiring in the different sessions, both in theory and in practice, according to the development of the Didactic Units proposed. Likewise, certain practice sessions will be dedicated to the manufacture by the students of the prototypes of the pieces of their respective projects, under the premise that "to make, one learns by doing".

Each group will choose the automotive piece they want to design or redesign. The aspects proposed to treat/develop in the project, as partial objectives, are presented to the students before starting and are the following:

- Context: introduction and justification of the selection of the piece.

- 3D modeling of the current piece: CAD design and analysis of the materials currently used (properties of the materials used and justification of why they are used today).

- Simulations of stress states and workloads on the actual piece: aerodynamic, mechanical, thermal loads, fatigue, impact, etc. Establishment of the fastenings, the boundary conditions, the loads, and the current materials. Analysis of the results of the simulations carried out using tools based on the finite element method.

- Restyling of the project piece: CAD redesign of the piece, including analysis and selection of new materials for manufacture.

- CAE simulations of the new redesigned part: comparison of results obtained from the redesign piece vs. results of the original piece simulations.

- Model and functional prototype manufacture of the redesigned piece.

Figure 1 shows the example of the project carried out by one of the student groups of the subject. In this case, the project consisted in the redesign of the Airbox of a competition motorcycle. After finishing the project, the students managed to obtain and manufacture a prototype of the selected piece that was lighter than the original and able to withstand the physical and thermal conditions that occur in a motorcycle in a space very close to the engine. Figure 1 shows the 3D modeling that the students made of the piece, the temperature analysis of it and the prototype made with carbon fibre reinforced composite material.

Finally, regarding the evaluation, it is worth mentioning that the project constitutes $30 \%$ of the subject's grade and is made up of three parts: memory, defense-presentation and prototype. These three parts have the same weight, $10 \%$ each. The memory and the prototype are evaluated by the teacher, but as for the defense of the project, the evaluation is made both by the teacher, and among equals, using a rubric designed for that purpose.

\section{RESULTS}

The implementation of the Project Based Learning methodology in the "Materials. Design and Restyling" subject has led to satisfactory results for both teachers and students. In this case, by means of this methodological instrument, all the students who have followed the subject have passed. In addition, the final average note obtained in the subject has been higher than in previous years, as can be seen in Figure 2. This increase in the average note is the result of a greater degree of student participation and an improvement in the acquisition of knowledge by the students provided by the methodology introduced. 

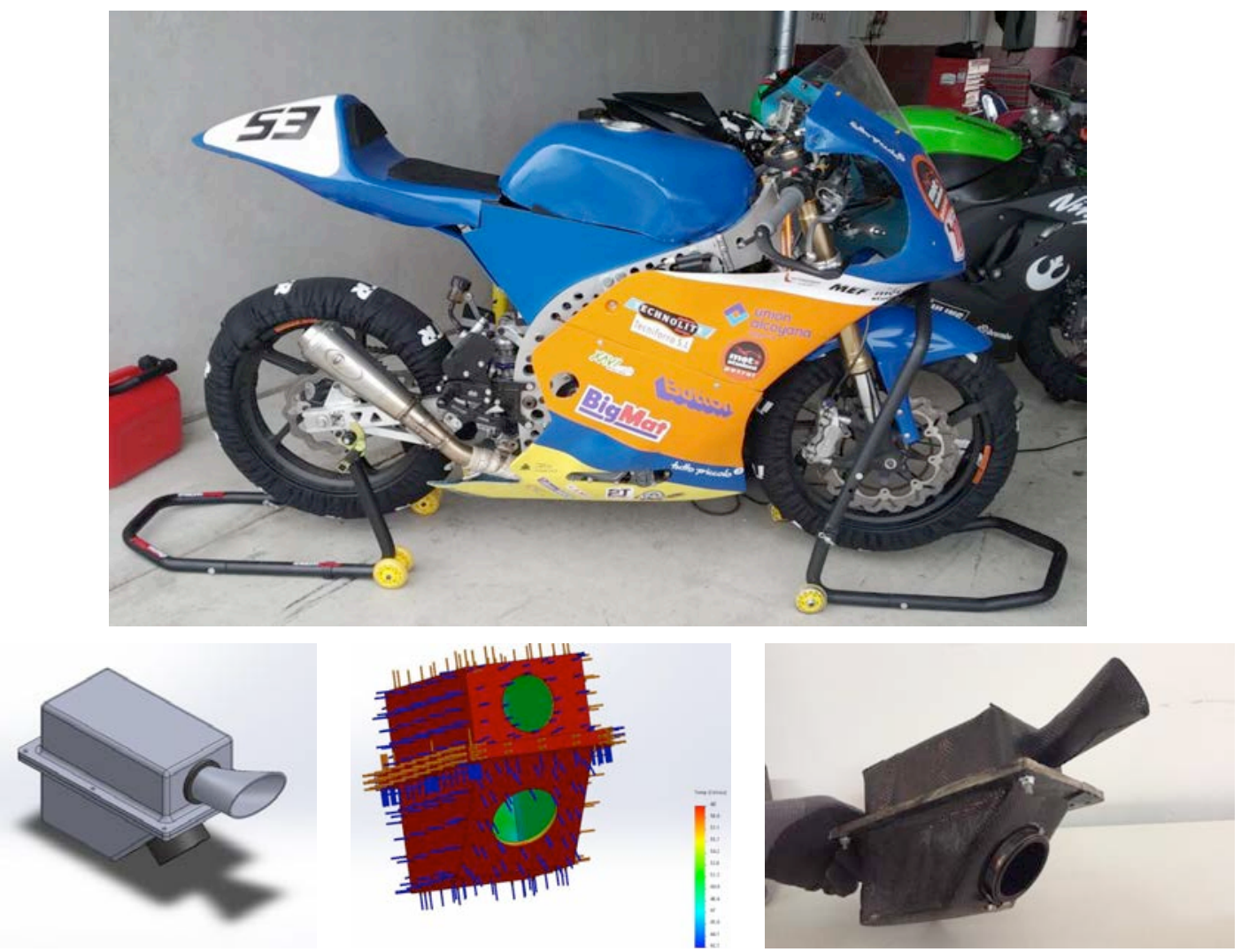

Figure 1. Images of the project carried out by the students.

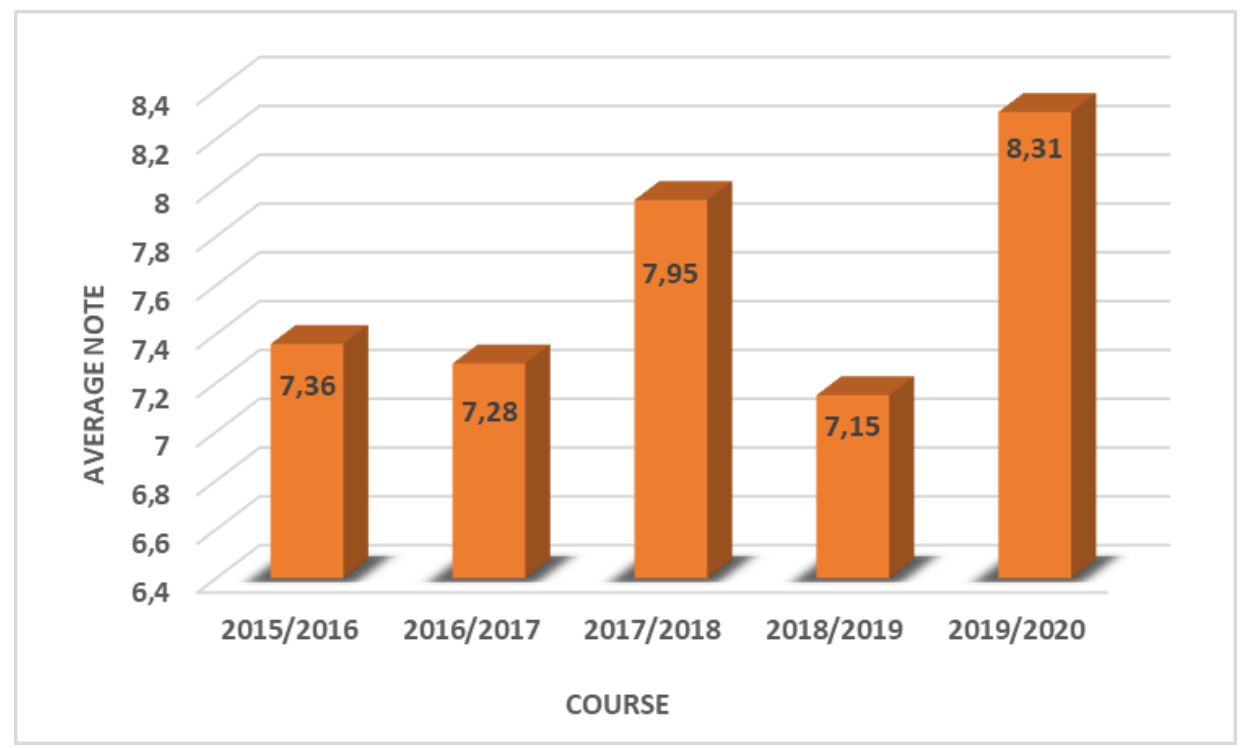

Figure 2. Average note of the subject "Materials. Design and Restyling" in the last five courses.

As mentioned above, the methodological instrument implemented improved the students' participation in the classes of the subject as well as the cooperation among them. This could be observed in the generation of numerous internal debates during the classes between the members of the group, as well as between different groups with respect to the development of the different proposed projects. In addition, there was also greater feedback between the students and the teacher in order to solve the problems that appeared during the development and execution of the projects.

Due to the fact that it was the first year that the Project Based Learning methodology was implemented in the subject "Materials. Design and Restyling" subject, it was decided to carry out an anonymous survey among the students in order to evaluate the methodology used in the subject and their satisfaction with its development. The survey performed, Figure 3 , consisted of 10 questions to 
which the students had to answer each of the questions with a scale of 1 to 5 , where 1 meant totally disagree and 5 meant totally agree.

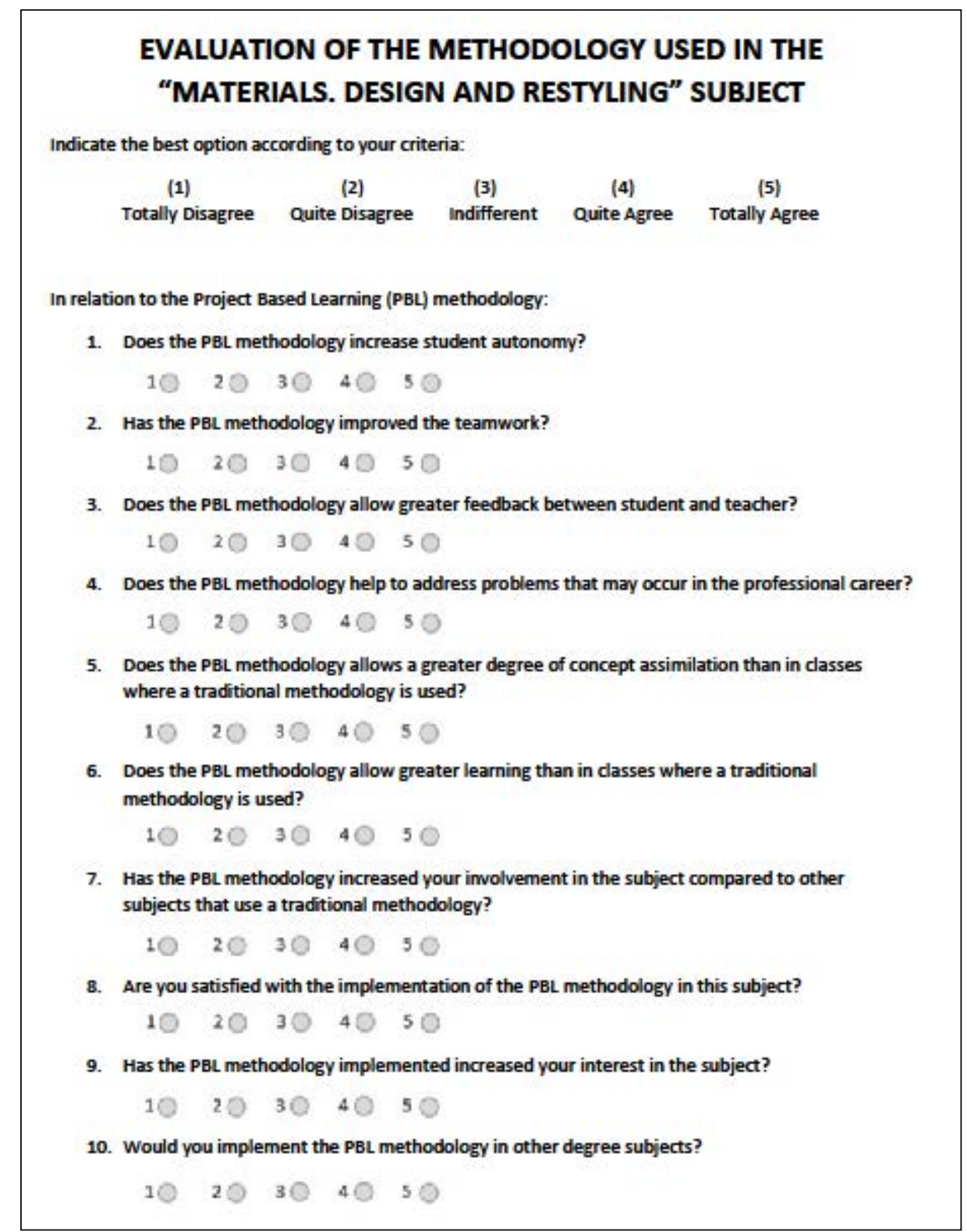

Figure 3. Survey performed by students for the evaluation of the Project Based Learning (PBL) methodology.

In this case the survey was performed by 23 of the 25 students who were matriculated in the "Materials. Design and Restyling" subject. The results obtained after the evaluation survey about the PBL methodology carried out by the students of the subject are shown in Table 1.

Once the results of the student survey have been analysed, a series of conclusions about the introduced methodology are obtained, which are very interesting for the teachers involved in the implementation of the methodology. The following conclusions have been obtained:

- All students are satisfied with the PBL methodology implemented in the subject. In addition, all of them would implement this methodology in other subjects of the Mechanical Engineering degree.

- Most of the students think that the PBL methodology improves the autonomy of the student in class, the teamwork and the feedback between student and teacher.

- Most of the students think that through the PBL methodology the concepts assimilation and the learning achieved is greater than in classes where a traditional methodology is used. 
- The vast majority of students, about $87 \%$, think that their degree of involvement in the subject has been greater with the application of PBL methodology than in classes where a traditional methodology is used.

- Finally, most of the students think that the PBL methodology has increased their interest in the subject.

Table 1. Results of the survey performed by students for the evaluation of the Project Based Learning (PBL) methodology.

\begin{tabular}{|c|c|c|c|c|c|}
\hline \multirow[b]{2}{*}{ QUESTION } & \multicolumn{5}{|c|}{ NUMBER OF STUDENTS } \\
\hline & 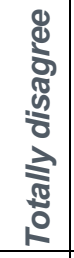 & 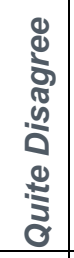 & 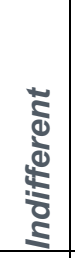 & 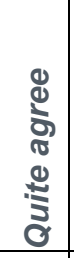 & 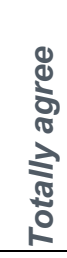 \\
\hline 1. Does the PBL methodology increase student autonomy? & 0 & 0 & 2 & 4 & 17 \\
\hline 2. Has the PBL methodology improved the teamwork? & 0 & 0 & 0 & 7 & 16 \\
\hline $\begin{array}{l}\text { 3. Does the PBL methodology allow greater feedback between } \\
\text { student and teacher? }\end{array}$ & 0 & 0 & 4 & 4 & 15 \\
\hline $\begin{array}{l}\text { 4. Does the PBL methodology help to address problems that } \\
\text { may occur in the professional career? }\end{array}$ & 0 & 1 & 4 & 3 & 15 \\
\hline $\begin{array}{l}\text { 5. Does the PBL methodology allows a greater degree of } \\
\text { concept assimilation than in classes where a traditional } \\
\text { methodology is used? }\end{array}$ & 0 & 0 & 2 & 7 & 14 \\
\hline $\begin{array}{l}\text { 6. Does the PBL methodology allow greater learning than in } \\
\text { classes where a traditional methodology is used? }\end{array}$ & 0 & 0 & 2 & 6 & 15 \\
\hline $\begin{array}{l}\text { 7. Has the PBL methodology increased your involvement in the } \\
\text { subject compared to other subjects that use a traditional } \\
\text { methodology? }\end{array}$ & 0 & 0 & 0 & 3 & 20 \\
\hline $\begin{array}{l}\text { 8. Are you satisfied with the implementation of the PBL } \\
\text { methodology in this subject? }\end{array}$ & 0 & 0 & 0 & 0 & 23 \\
\hline $\begin{array}{l}\text { 9. Has the PBL methodology implemented increased your } \\
\text { interest in the subject? }\end{array}$ & 0 & 0 & 3 & 5 & 15 \\
\hline $\begin{array}{l}\text { 10. Would you implement the PBL methodology in other degree } \\
\text { subjects? }\end{array}$ & 0 & 0 & 0 & 0 & 23 \\
\hline
\end{tabular}

\section{CONCLUSIONS}

The experience with the implementation of the Project Based Learning (PBL) methodology in the "Materials. Design and Restyling" subject of the Mechanical Engineering degree taught at the Higher Polytechnic School of Alcoy of the Universitat Politècnica de València (UPV) has been highly satisfactory and widely accepted by students as shown by the results obtained in surveys performed anonymously. The result of the survey highlights the students' satisfaction with the methodological instrument implemented in the subject, and their interest in introducing this methodology in other subjects of the degree.

It should be noted that the implementation of the PBL methodology in the subject "Materials. Design and Restyling" has provided a number of benefits in the development of this subject, among which are a greater involvement and participation of students in class or a better assimilation of the concepts discussed in it, which has been reflected in an increase in the average final note of the subject with respect to previous courses. Other important points observed in the implementation of the Project Based Learning (PBL) methodology have been the greater autonomy of the students in learning, the increase in cooperation between groups and the possibility of decision making by the students to deal with the resolution of the project proposed in the subject. 
Due to the positive experience obtained with the implementation of the Project Based Learning methodology, reflected in the good results obtained by the students, as well as in the increase in motivation and participation of the students during the subject development, it is intended to continue with this methodology in subsequent years and even apply it to other subjects of the Mechanical Engineering degree that have a practical character.

\section{ACKNOWLEDGEMENTS}

This article has been supported by Universitat Politècnica de València, particularly by the Vicerectorate for Digital Resources and Documentation (Vicerrectorado de Recursos Digitales y Documentación) and Vice-Rectorate for Studies, Quality and Accreditation (Vicerrectorado de Estudios, Calidad y Acreditación) under the Call for Learning + Teaching (Convocatoria A+D2019: Aprendizaje + Docencia. Proyectos de Innovación y Mejora Educativa) and Project Code: A157. The authors would like to acknowledge the support of the Institute of Educational Sciences (Instituto de Ciencias de la Educación), the Evaluation and Monitoring Commission for Educational Innovation and Improvement Projects (Comisión de Evaluación y Seguimiento de Proyectos de Innovación y Mejora Educativa (CESPIME) and Escuela Politécnica Superior de Alcoy.

\section{REFERENCES}

[1] P. M. Díaz, "Metodología de enseñanza universitaria: la mejora de la situación de enseñanzaaprendizaje en las aulas universitarias." pp. 113-140.

[2] A. Fernández March, "La evaluación orientada al aprendizaje en un modelo de formación por competencias en la educación universitaria," REDU. Revista de Docencia Universitaria, vol. 8, no. 1, pp. 11-34, 2011.

[3] D. R. Muñoz, and D. H. Araya, "Los desafíos de la evaluación por competencias en el ámbito educativo," Educação e Pesquisa, vol. 43, no. 4, pp. 1073-1086, 2017.

[4] P. Toledo Morales, and J. M. Sánchez García, "Aprendizaje basado en proyectos: Una experiencia universitaria," 2018.

[5] J. G. Martín, and J. E. P. Martínez, "Aprendizaje basado en proyectos: método para el diseño de actividades," Revista Tecnología, Ciencia y Educación, no. 10, 2018.

[6] A. M. Botella Nicolás, and P. Ramos Ramos, "Investigación-acción y aprendizaje basado en proyectos. Una revisión bibliográfica," Perfiles educativos, vol. 41, no. 163, pp. 127-141, 2019.

[7] J. J. Solaz-Portolés, V. S. López, and Á. G. López, "Aprendizaje basado en problemas en la Educación Superior: una metodología necesaria en la formación del profesorado," Didáctica de las ciencias experimentales y sociales, 2011.

[8] P. Sanz Morales, “La enseñanza a través del Aprendizaje Basado en Proyectos," 2017.

[9] R. Sanchis, J. Mula, B. Cantó Colomina, D. Garcia-Sanoguera, J.I. Torregrosa López, "Diseño de la Incorporación del Aprendizaje Basado en Proyectos en las Titulaciones de Grado del Campus de Alcoy de la Universitat Politècnica de València", VI Congreso Nacional de Innovación Educativa y Docencia en Red, Editorial Universitat Politècnica de València, 2020.

[10] J. Linares-Pellicer, J. Orta-López, J. Salavert-Torres, M.J. Segura Flor, J.A. Silvestre Cerdà, R. Sanchis, "Towards Inter-Subject Project-Based Learning in Programming-Related Courses at Computer Science Studies", EDULEARN Proceedings, pp. 3973 - 3978, 2020.1

[11] J. Esparza Peidro, E.J. Golf Laville, J.J Izquierdo-Doménech, J.V. Tomas Miquel, R. Sanchis, "Definition of Project-Based Learning Models in the Computer Engineering Degree", EDULEARN Proceedings, pp. 3966 - 3972, 2020.

[12] M. Pérez-Sánchez, M. Díaz-Madroñero Boluda, J. Mula, R. Sanchis, "The Sustainable Development Goals (SDGs) Applied to Higher Education. A Project Based Learning Proposal Integrated with the SDGs in Bachelor Degrees at the Campus Alcoy (UPV)", EDULEARN Proceedings, pp. 3997 - 4005, 2020.

[13] R. Balart, N. Montanes, L. Quiles-Carrillo, S. Jordá-Gisbert, H.C. Sanchis-Gomis, Sanchis, R., "Model Design and Calculation with Polymeric and Composite Materials through Project-Based Learning", EDULEARN Proceedings, pp. 3979 - 3986, 2020 
[14] M. Pérez-Sánchez, R. Sanchis, "Sustainable Development Goals Integrated in Project-Based Learning in the Mechanical Engineering Degree", INTED Proceedings, 2021.

[15] C. Carbonell, S.C. Cardona, I. Domínguez, V. Fombuena, M.F. López-Pérez, J. Lora, R. Sanchis, " Project-based learning as a coordination methodology between subjects in a Chemical Engineering degree", INTED Proceedings, 2021. 